\title{
ECONOMIE
}

ECONOMY

\section{Pig meat price. Analysis of the last three decades}

\author{
A. VIGNE, M. RIEU \\ I.T.P., 34, boulevard de la Gare, 31500 Toulouse \\ France
}

The monthly production price series of pig meat in France over a period of 30 years was analysed. Four main elements were noted :

- a general slightly upward trend (6 p. 100 only per year during the last decade) in nominal terms which leads to a serious deterioration in real terms (between -3 and -4 p. 100 a year during the same decade on an average) ;

- a persistent cycle of about 3 years up till 1974-1975 and of 2 years from then on. The amplitude compared to the general trend is about 6 to 8 p. 100 ;

- a seasonal influence, the amplitude of which is attenuated with time, but remains at certain periods of the year as high as \pm 2 p. 100 ;

- a random short term fluctuation usually within the limits of \pm 2 p. 100 but which can reach 5 to 6 p. 100 .

\section{Seasonal fluctuations in pig meat market}

\author{
P. MAINSANT, A. VIGNE * \\ I.N.R.A., Laboratoire de Recherches et d'Etudes sur l'Economie \\ des: Industries agricoles et alimentaires, 3, rue du Caducée, B.P. 333, \\ 94153 Rungis Cedex \\ I.T.P., 34, boulevard de la Gare, 31500 Toulouse \\ France
}

The main target of this study was to analyse the seasonal phenomena of the French and E.E.C. pig markets and to explain the seasonal price variations of pig carcasses in France. Our study was based on the seasonal coefficients of existing statistical series.

Although the seasonal profiles of carcass prices of all the E.E.C. countries are in phase, the amplitudes differ sharply. The French amplitude is markedly beyond all the others. This difference in fluctuation amplitude makes the French market attractive in the springtime and summer and brings about a seasonal inflow from other countries at this period.

This particularity of the French market, as well as the seasonal profile of carcass prices in France are determined by the seasonal character of French retail demand of main cuts. The mechanism of this relationship is very complex. In fact, though each cut is subjected to great seasonal variations, these variations partly counterbalance one another at the carcass level. Nevertheless, processing industries still regulate the market of each cut by seasonal imports or by stocking particular cuts. 